\title{
The Qualitative Analysis and Application of Course Classification in Job-oriented Professional Education
}

\author{
Jianwei Lv \\ Dept of Management Science \\ Naval Univ. of Engineering \\ Wuhan, China \\ L2015wh@163.com
}

\author{
Zongren Xie \\ Dept of Management Science \\ Naval Univ. of Engineering \\ Wuhan, China \\ Wx1839@hotmail.com
}

\author{
Peng Di \\ Dept of Management Science \\ Naval Univ. of Engineering \\ Wuhan, China
}

\begin{abstract}
The characteristics of job-oriented professional education (professional train) are analyzed. The knowledge systems of trainee in training are explored. From the point of the knowledge systems, six arrangements of training needs are given. By the views of trainee, considering the need of knowledge system and knowledge fusion, the course classification is analyzed. The training course is divided into Independent, Significant, Related and Duplicated types. With the classical samples, qualitative analysis model, examples and the definitions of course classification are presented. Application and further research directions of next step are prospected.
\end{abstract}

Keywords-professional education; knowledge system; knowledge fusion; course classification; application

\section{INTRODUCTION}

Job-oriented professional education is built on the basis of academic education. It's a special train that aims to make trainees obtained professional theories and practical skills, as well as the capacity of being competent for their current work. Its basic guideline is that it is a kind of the train based on the university education, and of job-oriented demands with the aim to capacity development further ${ }^{[1]}$. During the train process, for all the trainees, they will face with problem of the fusion of several (two or more) knowledge systems. At the same time, for the school, to each course and its contents in training program, whether it meets the needs of the trainees, whether it is easy to get the fusion of knowledge, what the training-program-maker firstly should do is to identify each course, i.e. the positioning and classification of course. All of these are related to knowledge fusion and course classification between the trainee's previous knowledge system and training program. For the lack of systematic research in this field, the paper will give a preliminary discussion and analysis.

\section{THE KNOWLEDGE System AND NEED ANALYSIS IN PROFESSIONAL EDUCATION}

In job-oriented professional education, the characteristics of the trainees include: (1) all of them usually have got formal academic education and have their own previous majors(previous knowledge systems); (2) they all have their own jobs (but jobs may not match the previous major); (3) technical fields and equipments that various trainees are faced with are different, i.e., they are involving in wide professional ranges due to the kinds of naval equipments; (4) they have graduated from colleges and have been working for a period of time; (5) they come to learn knowledge and skills on some job-related fields (such as equipment's logistics and support); (6) they will return to their units and be engaged in the related work after this job-oriented train.

From the above characteristics, three knowledge systems with which each of the trainees may face can be identified, namely: (1) the previous academic education system; (2) the knowledge system that the current jobs request; (3) the knowledge system determined in the training program of this job-oriented education. Shown in Fig.1.

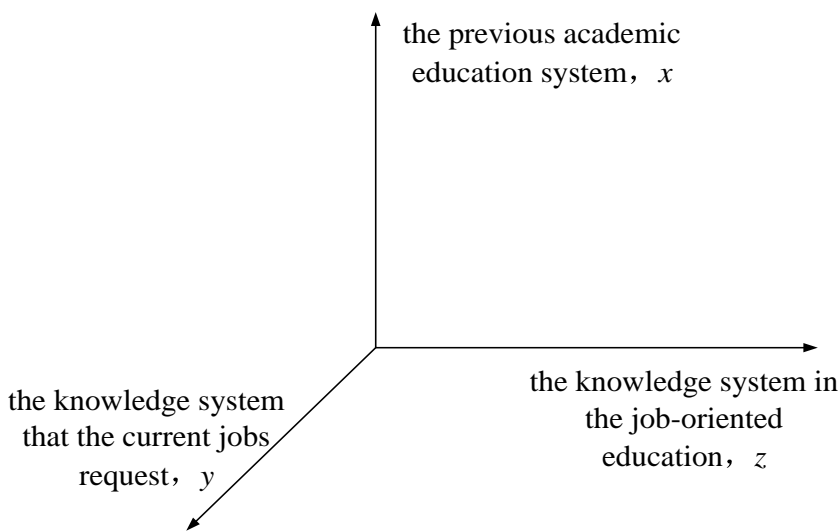

Figure 1. The knowledge systems that trainees are faced with 
In Fig.1, the three knowledge systems correspond to three types of jobs, their relationship is shown in Tab. I.

The previous knowledge system $x$ are available from the previous academic education for trainees, which corresponds to the expected jobs at that time.

TABLE I. KNOWLEDGE SySTEMS AND JobS THAT TRAINEES ARE FACED WITH

\begin{tabular}{|c|c|c|}
\hline No. & Knowledge systems & Jobs \\
\hline 1 & $\begin{array}{c}\text { The previous academic } \\
\text { education system, } x\end{array}$ & $\begin{array}{c}\text { Expected jobs in the } \\
\text { academic education, } a\end{array}$ \\
\hline 2 & $\begin{array}{c}\text { The knowledge system that } \\
\text { the current jobs request, } y\end{array}$ & Current jobs, $b(b 1, b 2)$ \\
\hline 3 & $\begin{array}{c}\text { The knowledge system in the } \\
\text { professional education, } z\end{array}$ & $\begin{array}{c}\text { Expected jobs in the } \\
\text { future, } c\end{array}$ \\
\hline
\end{tabular}

The knowledge system that the current jobs request, is possible consistent with the previous knowledge system, namely, this is the situation in which the major matches the job requirement $(a=b)$, so, $x=y$, there is no need to train further in theory. Otherwise, that is $x \neq y$. In this case, some trainees may have basically mastered the necessary knowledge ( $b 1)$ which is enough to deal with the job requests by self-study. But someone may have not mastered (b2), if so, it will be necessary for them to learn knowledge and skills in school (the spontaneous training requirement).

The knowledge system $z$ is aimed at the future job's requirement of each trainee. If we assume that trainees' current jobs are consistent with the expected work in the future $(b=c)$, then in circumstance $b 1$, there is no or almost no training requirements. In circumstance $b 2$, the training is quite necessary. In the case $b \neq c$, it's still necessary for trainee to participate in the professional education.

From the correspondence relationship above, six cases can be identified. Shown in Tab.II.

In Tab.2, the possibility of the occurrence of the first case (No.1) is quite small (professional counterparts, and knowledge system of the academic education is in line with the work requirements completely). If so, there is also the requirements of the updating and improvement of the knowledge system. The possibility of the third case (No.3) is small too (in the case, there is no identical professional basis, but trainees have been fully able to meet the work requirements entirely through self-study). If so, there are still the requirement of the systematization and improvement of knowledge system. Thus it can be inferred from the Tab.2 that the training requirements for professional education are widespread in theory.

Of course, the second, fifth, sixth cases should also not appear. It is equivalent to converting major through the train of this time, which rarely occurs in real work. And about some trainees are about to be transferred to civilian work (out of their origin military jobs) immediately after this train, it has violated the purpose of the professional education. In the real work, there should be more the third (No.3) and the fourth (No.4) cases. Further analysis will be focused on these two cases, as well as the first case (No.1).
Accordingly, it will occur $y=z$ without considering $b \neq c$. Then the Fig.1 is transferred to an ichnography. Shown in Fig.2.

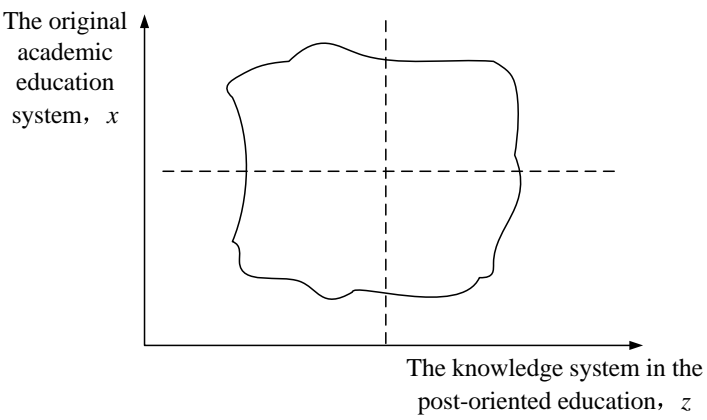

Figure 2. The knowledge systems that trainees are faced with (simplified)

Based on these cases, the qualitative modeling and analysis will be taken to the course classification relationships in the professional education as follows.

\section{THE PRELIMINARY ANALYSIS OF THE COURSE \\ CLASSIFICATION IN THE PROFESSIONAL EDUCATION}

In term of the current conditions, it is impossible to adopt individual training or classification teaching with a large number of small classes in a train. The training program is almost set for all the trainees uniformly.

In these circumstances, the training program ( $\left.z=\left\{z_{1}, z_{2} \ldots \ldots z_{n}\right\}\right)$ designed in the professional education cannot be set for each individual in theory, which may combine with the course $\left(x=\left\{x_{1}, x_{2} \ldots . x_{n}\right\}\right)$ in the previous knowledge system. It is because two knowledge systems are not formed simultaneously in Fig.2 and all trainees have received a unified training program. In this case, what we can do is only focusing on analysis of the process and program of the professional education. I.e., for each trainee, it is compared between the core course of their previous majors and the course in this training program. Then the relationship between them will be identified through some models or methods, which can be classified as some categories and simply denoted by $S_{i}=S\left(z_{i} \mid x\right)$. It indicates the characteristic ascription of a certain course $z_{i}$ in this training program, which is based on the previous knowledge system $x$. (if the conditions are enough, the quantitative indicators or ascription value can be further explored).

The purpose of this analysis is to provide all the courses' systematic information and study strategies for each trainee, 
TABLE II. Six PERmutations OF The TraineEs’ Training REQUiREMENTS

\begin{tabular}{|c|c|c|c|c|}
\hline NO. & $\begin{array}{l}\text { Correspondences of } \\
\text { the knowledge system }\end{array}$ & Correspondences of jobs & $\begin{array}{l}\text { Whether have training } \\
\text { requirements or not }\end{array}$ & The training requirements \\
\hline 1 & $x=y=z$ & $a=b=c$ & Seemingly no & $\begin{array}{l}\text { The updating and improvement of } \\
\text { knowledge system }\end{array}$ \\
\hline 2 & $x=y \neq z$ & $a=b \neq c$ & yes & Systematic requirements \\
\hline 3 & $x \neq y=z$ & $a \neq b 1=c$ & Seemingly no & $\begin{array}{l}\text { Systematization and improvement of } \\
\text { knowledge system }\end{array}$ \\
\hline 4 & $x \neq y=z$ & $a \neq b 2=c$ & yes & $\begin{array}{l}\text { Complementarities and improvement of } \\
\text { knowledge system }\end{array}$ \\
\hline 5 & $x \neq y \neq z$ & $a \neq b 1 \neq c$ & yes & Systematic requirements \\
\hline 6 & $x \neq y \neq z$ & $a \neq b 2 \neq c$ & yes & Systematic requirements \\
\hline
\end{tabular}

which can help them with the process of knowledge fusion. In other words, the fusion of course and knowledge ${ }^{\text {i2- }}$ 4] is completed by themselves individually. At the same time, the analysis process and results can also provide useful information of the course locating, etc.

At present, we have adopted this method in the training programs, the courses in the training program have been initially divided into: Independent Course (IC), Significant Course (SC), Related Course (RC) and Duplicated Course $(D C)$ and so on. I.e.,

$$
S=\left\{S\left(z_{i} \mid x\right)\right\}=\left\{S_{1}, S_{2}, \ldots \ldots, S_{m}\right\}=\{I C, S C, R C, D C ., \ldots \ldots .\}
$$

Shown in Fig.3.

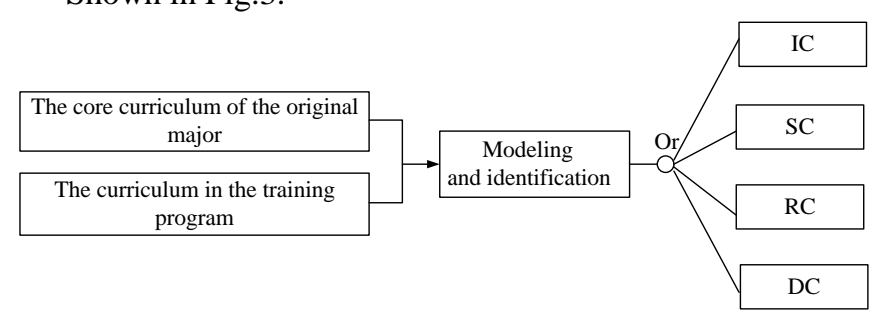

Figure 3. The modeling and identification process of course classification in professional education

\section{SAMPLES AND QUALITATIVE ANALYSIS}

\section{A. Sample and Modeling}

Suppose that a sample trainee's previous major is marine propulsion engineering, its previous core course ( $x$ type) are: the internal-combustion engine, engineering mechanics, dynamo and vibration, impeller machinery, ship auxiliary machinery, ship machinery foundation.

There is a training program in this job-oriented education. Its core courses (z) include Project Management $z_{1}(\mathrm{PM})$, Ship Electrical Equipment $z_{2}(S E E)$, Equipment Maintenance Management $z_{3}(E M M)$, etc.

The qualitative analysis method to determine the characteristics of course is to compare course $z_{i}$ in z-class with all course in $x$-class. Then the characteristics of the course will be determined through qualitative analysis (expert investigation or subjective analysis). It is like that

$$
S\left(z_{i} \mid x\right)=\left(z_{i}\right)\left(\begin{array}{c}
x_{1} \\
x_{2} \\
\ldots \\
x_{n}
\end{array}\right)=S_{i}
$$

Equation (2) does not mean making some vectors multiplication, but comparing course $z_{i}$ with all courses in $x$-class. The relationship between $z_{i}$ and $\mathrm{x}$ will be obtained by analysis and judgment, which equals to the value of formula (1). Below are several examples.

For the course Project Management $z_{1}(P M)$ in $z$-class, the model is described as follows.

$$
S_{1}=S\left\{z_{1} \mid x\right\}=(P M)\left(\begin{array}{l}
\text { the internal - combustion engine } \\
\text { engineerin } \mathrm{g} \text { mechanics } \\
\text { dynamo and vibration } \\
\text { impeller machinery } \\
\text { ship auxiliary machinery } \\
\text { ship machinery foundation }
\end{array}\right)=\{I C\}
$$

After analysis and comparison, it proves to be an Independent Course. In the current training program, this course belongs to the "basic platform" type. It has certain basal characters, and it is naturally independent with the previous course.

For the course Ship Electrical Equipment $z_{2}(S E E)$ in $z-$ class, the model is

$S_{3}=S\left\{z_{3} \mid x\right\}=(S E E)\left(\begin{array}{l}\text { the internal - combustion engine } \\ \text { engineerin g mechanics } \\ \text { dynamo and vibration } \\ \text { impeller machinery } \\ \text { ship auxiliary machinery } \\ \text { ship machinery foundation }\end{array}\right)=\{R C\}$

Compared with the previous courses, it can be called Related Course (nature-same course). 
For the course Equipment Maintenance Management $z_{3}(E M M)$ " in $z$-class, the model is

$$
S_{2}=S\left\{z_{2} \mid x\right\}=(E M M)\left(\begin{array}{l}
\text { the internal - combustion engine } \\
\text { engineerin g mechanics } \\
\text { dynamo and vibration } \\
\text { impeller machinery } \\
\text { ship auxiliary machinery } \\
\text { ship machinery foundation }
\end{array}\right)=\{S C\}
$$

By comparison, for the trainees' jobs in the future, it's considered as a significant basis course, which can be called the Significant Course for short. Due to the limited space, we will not repeat them here.

\section{B. Course Type and Analysis}

Through the analysis and modeling above, the following course types can be defined, which are produced based on the trainees' previous knowledge systems and the expected work in the future.

The Independent Course(IC): the course those are completely or almost irrelevant with the trainees' previous knowledge systems.

The Significant Course (SC): the important basal course for the expected work in the future.

The Related Course (RC) (or the nature-same course): for trainees' previous knowledge systems, it equals to add a same type of course.

The Duplicated Course $(D C)$ : the course that is completely or almost repeated with the previous knowledge systems.

During our analysis, we realize there are some other course types in the training program, Due to the limited space, not mentioned further.

\section{APPLICATION}

In our work, we carry out the modeling and analysis for each trainee, or try to give our advice to every trainee, to urge them complete the analysis by themselves. The influences are quite obvious, i.e. :(1) to deepen the understanding to each course (its status and effect); (2) to help trainee adopt different study strategies (to independent, significant, sub-significant, related, non-key course, etc), so as to complete the depth knowledge fusion ${ }^{[5]}$ process with reference to the characteristics of each course; (3) to help trainees give their suggestions timely in the training process because of the accurate locating and classification.

For the trainers, the effects of the analyses are mainly reflected in: (1) to take this opportunity to fully understand the basic information of the trainees and their backgrounds, then to make the targeted training; (2) to help teachers carry out the course locating; (3) to optimize the training programs through identifying the duplicated and unnecessary course.

Now we have adopted above models and method in several training classes. For example, for a class with 15 trainees, to each person, $I C, S C, R C$, etc. in the training plan had been identified as soon as they arrived at school, which deepen their understandings to each course in the training plan and increased their initiative in the training. Through the process, the trainers quickly identify out a $D C$ and a subSignificant course (to most trainees) and delete them. For the $S C$ to most trainees, trainers will have strengthened appropriately, which has played a satisfying role in optimizing this training program.

\section{FURTHER RESEARCH DIRECTIONS}

Until to now, the analysis to relationship between various knowledge systems and the elements in professional education has just been at the preliminary stage, in which the models are only qualitative and judging by person, the methods are only in terms of some typical cases. The further research included: (1) with the collection of samples, for trainers, they could create quantitative models and the model outputs statistics. Besides, they can compute the importance degree of each course classification in the training plan. For trainees, they can find the knowledge deficiency combined with the scenario analysis and other methods; (2) in broad sense, the course classification is only the first step. In the professional education, what is really needed in-depth study are the course fusion and trainees' knowledge fusion. In these fields, further efforts will be made.

\section{ACKNOWLEDGMENT}

Support by Education Research Foundation of Naval University of Engineering, Grant No: HJJ20100601

\section{REFERENCES}

[1] LV Jianwei, HU Tao, WEI Jun, YANG Jianjun, YANG Chunhui. On the Approaches of Requirements Analysis on job-oriented Education[J].Journal of Naval University of Engineering, 2012, 9(1):47-50.

[2] LV Jianwei, ZHANG Weihong, YANG Jianjun. The Research of Lecture-Mode in Teaching the job-Oriented Education[J]. Journal of Higher Education Research, 2012, 35(4):99-101.

[3] JU Chunhua, ZHOU Yi. The Integration of IT Knowledge and Knowledge of Finance and Economics in Teaching Reform[J]. China Higher Education Research, 2006, (12):82-83.

[4] YU Yun. Discussion of Information Literacy Education From the Perspective of Course Integration[J]. Modern Educational Technology, 2008, 18(13):45-47.

[5] WANG Xiaoqi, LIU Hai. The Mergence of Information Quality Education and Current Courses in Military Academies[J]. Journal of Higher Education Research, 2008, 31(3):23-26. 